\title{
Symptomatic Soft-Tissue Mass in the Intercondylar Notch: A Case Report
}

Athar MS'*, Ashwood N1, Hayward K1, Karagkevrekis B', Aggouris $\mathrm{K}^{2}$ and Fogg $\mathbf{Q}^{2}$

${ }^{1}$ Department of Trauma and Orthopaedics, Queens Hospital, Burton-on-Trent, UK

${ }^{2}$ Laboratory of Human Anatomy, School of Life Sciences, University of Glasgow, UK

*Correspondling author: M Sajjad Athar, Department of Trauma and Orthopaedics, Queen's Hospital, Burtonon-Trent, UK

Received: November 28, 2017; Accepted: J anuary 31, 2018; Published: February 08, 2018

\section{Introduction}

A list of neoplastic and reactive processes that form mass lesions in joints includes pigmented villonodular synovitis, synovial hemangioma, synovial chondromatosis, lipoma arbolescens, ganglion cyst, intra-articular nodular fasciitis and others [1]. The authors describe a quite unusual case of symptomatic soft tissue mass in the intercondylar notch which caused painful limitation in the range of motion compromising the patient's overall function.

\section{Case Presentation}

We present a case of a 48-year-old male patient who had been complaining of persistent stiffness with pain in his left knee for about one year. He was working as an electrician spending a lot of time kneeling on his knees and could not recall any previous injury.

On clinical examination the patient was unable to fully extend his knee having about 25 degrees of fixed flexion deformity. He could also only flex his knee to about 90-100 degrees with significant pain which did not allow him further flexion. There was no tenderness at the joint space. McMurray and Apley tests were negative and the knee was stable with Lachman, posterior drawer, and medial and lateral stress tests.

Plain radiographic findings were normal without notch enlargement on the intercondylar notch view and no evidence of any calcified tissue mass (Figure 1). MRI scan findings included a softtissue mass in the intercondylar notch (Figure 2), focal degenerative changes in the medial facet of the patella (Figure 3) with early cartilaginous changes in both medial and lateral compartments.

Arthroscopy was performed for further evaluation of the joint. Intraoperative findings included a small chondral flap on the medial femoral condyle (Figure 4), multiple small calcified loose bodies, and a soft tissue mass about $15 \mathrm{~mm}$ in diameter found to almost completely occupy the intercondylar notch (Figure 5). The surface of the mass was smooth on probing and it was impinging between the ACL and the intercondylar notch when the knee was extended. The chondral flap was trimmed with a basket forceps and the soft tissue lump was removed with a soft-tissue arthroscopic shaver exposing the

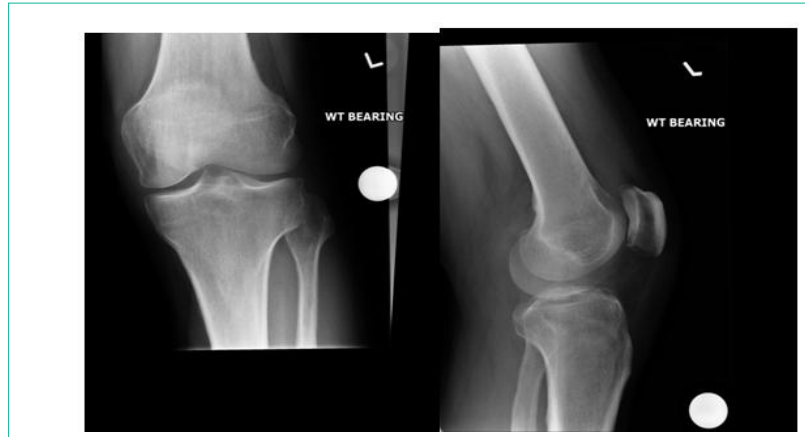

Figure 1: Plain radiographs were normal with no obvious bony pathology.

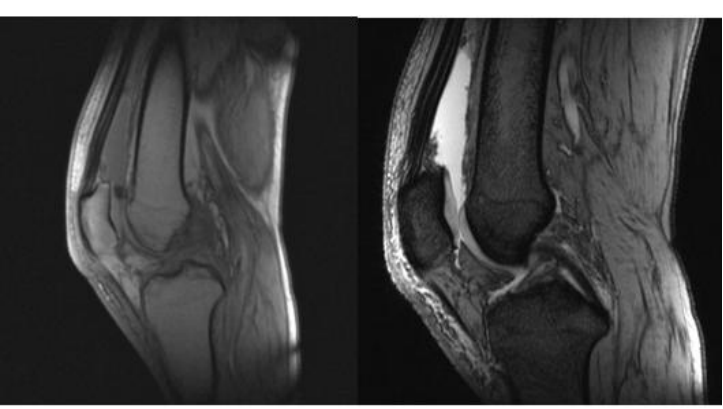

Figure 2: MRI scan revealing a soft tissue mass in the intercondylar notch anterior to the ACL.

intact ACL. Finally, there was no evidence of synovial proliferation or meniscal pathology and no evidence of gout or pseudogout on the specimens sent for microbiology.

The patient regained immediately almost full range of motion and remains symptom-free at 6 months postoperatively having returned to his previous level of activities.

\section{Discussion}

Flexion contractures of the knee may occur from many causes [24]. Intraarticular pathological conditions include congenital patellar dislocation, shortening of the anterior cruciate ligament, contracture
Austin J Orthopade \& Rheumatol - Volume 5 Issue 1 - 2018 ISSN: 2472-369X | www.austinpublishinggroup.com Athar et al. (๐) All rights are reserved
Citation: Athar MS, Ashwood N, Hayward K, Karagkevrekis B, Aggouris K and Fogg Q. Symptomatic Soft-Tissue Mass in the Intercondylar Notch: A Case Report. Austin J Orthopade \& Rheumatol. 2018; 5(1): 1062. 


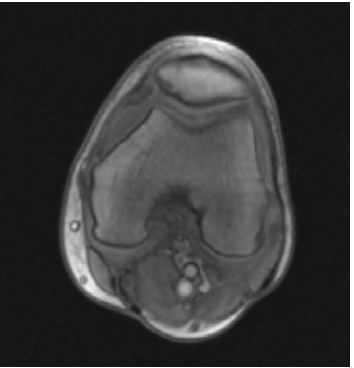

Figure 3: MRI scan showing focal degenerative changes in the medial patellar facet.

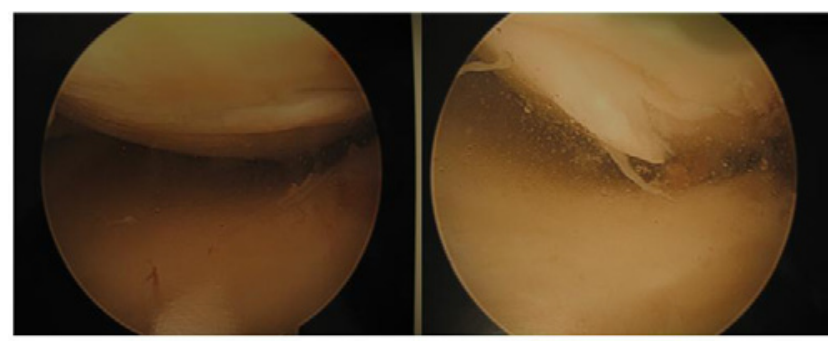

Figure 4: Cartilage flap on the medial femoral condyle.

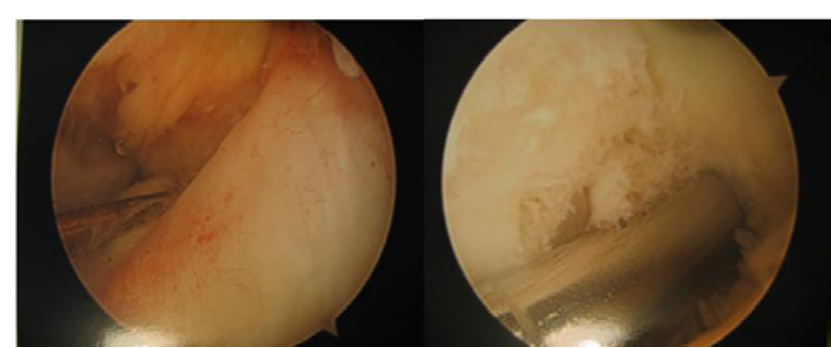

Figure 5: Soft-tissue mass occupying the intercondylar notch and removed with an arthroscopic shaver exposing the intact $A C L$. of the posterior capsule, loose bodies, meniscal tears, infrapatellar fat pad adhesions, irregularity of the opposing joint surfaces, infrapatellar plica or increased fluid volume in the joint. Another rare cause of limited extension of the knee joint is a ganglion cyst, which does not necessarily have to be associated with specific clinical symptoms or a previous trauma.

Because the intercondylar notch is relatively spacious, it may take time for the mass to develop dimensions large enough to cause symptoms [5]. Therefore, the relatively slow progression of symptoms may considerably delay the patient's decision to seek medical attention. When this lesion is discovered early, it can be treated successfully with an arthroscopic debridement. Delayed diagnosis makes total resection of the mass technically demanding or not possible at all and extensive debridement of the ACL may be required.

\section{References}

1. Enzinger FM, Weiss SW. Benign fibrous tissue tumors. In: Enzinger FM, Weiss SW, eds. Soft tissue tumors. St. Louis: Mosby, 1995; 165-199.

2. Bhan S, Rath S. Modified posterior soft tissue release for management of severe knee flexion contracture. Orthopedics. 1989; 12: 703-708.

3. Herzenberg JE, Davis JR, Paley D, Bhave A. Mechanical distraction for treatment of severe knee flexion contractures. Clin Orthop. 1994; 301: 80-88.

4. Mollinger LA, Steffen TM. Knee flexion contractures in institutionalized elderly: Prevalence, severity, stability, and related variables. Phys Ther. 1993; 73: 437-446

5. Krudwig WK, Schulte K-K, Heinemann C. Intra-articular ganglion cysts of the knee joint: A report of 85 cases and review of the literature. Knee Surg Sports Traumatol Arthrosc. 2004; 12: 123-129.
Austin J Orthopade \& Rheumatol - Volume 5 Issue 1 - 2018 ISSN: 2472-369X | www.austinpublishing group.com Athar et al. (C) All rights are reserved
Citation: Athar MS, Ashwood N, Hayward K, Karagkevrekis B, Aggouris K and Fogg Q. Symptomatic Soft-Tissue Mass in the Intercondylar Notch: A Case Report. Austin J Orthopade \& Rheumatol. 2018; 5(1): 1062. 